\title{
Use of a combined oxygen and carbon dioxide transcutaneous electrode in the estimation of gas exchange during exercise
}

\author{
M K Sridhar, R Carter, F Moran, S W Banham
}

\begin{abstract}
Background-Accurate and reliable measurement of gas exchange during exercise has traditionally involved arterial cannulation. Non-invasive devices to estimate arterial oxygen $\left(\mathrm{O}_{2}\right)$ and carbon dioxide $\left(\mathrm{CO}_{2}\right)$ tensions are now available. $A$ method has been devised and evaluated for measuring gas exchange during exercise with a combined transcutaneous $\mathrm{O}_{2}$ and $\mathrm{CO}_{2}$ electrode.
\end{abstract}

Methods-Symptom limited exercise tests were carried out in 24 patients reporting effort intolerance and breathlessness. Exercise testing was performed by bicycle ergometry with a specifically designed protocol involving gradual two minute workload increments. Arterial $\mathrm{O}_{2}$ and $\mathrm{CO}_{2}$ tensions were measured at rest and during exercise by direct blood sampling from an indwelling arterial cannula and a combined transcutaneous electrode heated to $45^{\circ} \mathrm{C}$. The transcutaneous system was calibrated against values obtained by direct arterial sampling before each test.

Results-In all tests the trend of gas exchange measured by the transcutaneous system was true to the trend measured from direct arterial sampling. In the 140 measurements the mean difference between the $\mathrm{O}_{2}$ tensions estimated by direct sampling and the transcutaneous method was $0.08 \mathrm{kPa}(0.62 \mathrm{~mm} \mathrm{Hg}$, limits of agreement 4.42 and $-3.38 \mathrm{~mm}$ $\mathrm{Hg})$. The mean difference between the methods for $\mathrm{CO}_{2}$ was $0.02 \mathrm{kPa}(0.22 \mathrm{~mm}$ $\mathrm{Hg}$, limits of agreement $2 \cdot 20$ and $-1.70 \mathrm{~mm} \mathrm{Hg}$ ). There was no morbidity associated with the use of the transcutaneous electrode heated to $45^{\circ} \mathrm{C}$.

Conclusions-A combined transcutaneous $\mathrm{O}_{2}$ and $\mathrm{CO}_{2}$ electrode heated to $45^{\circ} \mathrm{C}$ can be used to provide a reliable estimate of gas exchange during gradual incremental exercise in adults.

(Thorax 1993;48:643-647)

Non-invasive devices that estimate arterial blood gas tensions are now widely available and have been the subject of a recent comprehensive review. ${ }^{1}$ Pulse oximetry, ${ }^{2}$ transcutaneous monitoring of arterial oxygen $\left(\mathrm{O}_{2}\right)$ and carbon dioxide $\left(\mathrm{CO}_{2}\right)$ tensions, ${ }^{3}$ and monitoring of airway $\mathrm{CO}_{2}$ tensions ${ }^{4}$ are the techniques that are in use to provide a non-invasive estimate of gas exchange. This study evaluates the use of a combined $\mathrm{O}_{2}$ and $\mathrm{CO}_{2}$ monitor in the field of exercise testing.

The combined transcutaneous electrode consists of a Clark polarographic electrode that measures $\mathrm{O}_{2}$ and a modified Severinghaus glass $\mathrm{pH}$ electrode integrated into a single unit that can be applied directly to the skin. ${ }^{5}$ The unit also incorporates a thermostatically controlled heater which promotes local hyperaemia, enabling $\mathrm{O}_{2}$ and $\mathrm{CO}_{2}$ levels in cutaneous capillaries to approach arterial levels. While studies have shown that the combined electrode provides a reliable estimate of gas exchange in haemodynamically stable adult patients in the critical care setting, ${ }^{6}$ there has so far been no evaluation of the technique in exercise testing. We have attempted to develop this combined transcutaneous electrode for use in the measurement of gas exchange during exercise in adults.

\section{Methods}

Twenty four patients (15 men, nine women; age range 27-67 years) referred from respiratory or general medical clinics for a symptom limited progressive exercise test were studied. The group comprised patients with a range of cardiopulmonary disorders of varying degrees of severity, and also included patients with unexplained breathlessness (table). Referring clinicians cited various reasons for requesting exercise tests including: (1) an attempt to elucidate poor response to therapy (chronic obstructive pulmonary disease); (2) to define more precisely the cardiac $v$ respiratory component of exercise intolerance; or (3) further assessment of unexplained breathlessness in those patients with both normal electrocardiograms and standard lung function.

EXERCISE TESTING

Exercise testing was carried out by an electrically braked bicycle ergometer (Siemens Ltd) with the patient breathing through a low dead space, low resistance valve box. The valve box incorporated a turbine ventilometer on the inspired limb for the measurement of ventilation. Expired gas was analysed for $\mathrm{O}_{2}$ and $\mathrm{CO}_{2}$ content by an infrared spectrometer and 
Characteristics of the study population

\begin{tabular}{|c|c|c|c|}
\hline Diagnosis & $n$ & $\begin{array}{l}\text { Age range (y) } \\
\text { Sex }\end{array}$ & $\begin{array}{l}\text { Summary of cardiorespiratory } \\
\text { function }\end{array}$ \\
\hline $\begin{array}{l}\text { Chronic obstructive } \\
\text { pulmonary disease (COPD) }\end{array}$ & 8 & $\begin{array}{l}57-67 \\
5 \mathrm{M}, 3 \mathrm{~F}\end{array}$ & $\begin{array}{l}\text { Mean } \mathrm{FEV}_{1} 42 \% \text { predicted } \\
\text { (range } 34-67 \% \text { ) }\end{array}$ \\
\hline $\begin{array}{l}\text { Ischaemic heart } \\
\text { disease (IHD) }\end{array}$ & 5 & $\begin{array}{l}52-65 \\
3 \mathrm{M}, 2 \mathrm{~F}\end{array}$ & $\begin{array}{l}\text { ECG evidence of IHD; on } \\
\text { active treatment }\end{array}$ \\
\hline COPD and IHD & 2 & $\begin{array}{l}57 \text { and } 66 \\
2 M\end{array}$ & $\begin{array}{l}\text { Reduced } \mathrm{FEV}_{1} \text { and ECG } \\
\text { evidence of IHD }\end{array}$ \\
\hline $\begin{array}{l}\text { Pulmonary thromboembolic } \\
\text { disease }\end{array}$ & 2 & $\begin{array}{l}31 \text { and } 45 \\
2 F\end{array}$ & $\begin{array}{l}\text { Angiographically proven } \\
\text { pulmonary thromboembolism }\end{array}$ \\
\hline $\begin{array}{l}\text { Respiratory failure } \\
\text { due to scoliosis }\end{array}$ & 1 & $\begin{array}{l}46 \\
\mathrm{M}\end{array}$ & $\mathrm{FEV}_{1} 0 \cdot 7 \mathrm{l} ; \mathrm{VC} 1 \cdot 11$ \\
\hline $\begin{array}{l}\text { Hyperventilation } \\
\text { syndrome }\end{array}$ & 1 & $\begin{array}{l}27 \\
M\end{array}$ & $\begin{array}{l}\text { Normal FEV } 1, \text { TLCO } \\
\text { Normal ECG }\end{array}$ \\
\hline $\begin{array}{l}\text { Unexplained } \\
\text { breathlessness }\end{array}$ & 5 & $\begin{array}{l}32-54 \\
3 \mathrm{M}, 2 \mathrm{~F}\end{array}$ & $\begin{array}{l}\text { Normal cardiorespiratory } \\
\text { function }\end{array}$ \\
\hline
\end{tabular}

$\mathrm{FEV}_{1}$ - forced expiratory volume in one second; VC-vital capacity; TLCo-carbon monoxide transfer factor; ECG-electrocardiographic.

paramagnetic analyser respectively (PK Morgan, Rainham, Kent). The electrocardiogram was monitored throughout exercise. After a two minute rest while seated on the bicycle the patients were instructed to cycle with no additional load for two minutes. Thereafter the load was increased by $15-25$ W every two minutes until symptoms limited further exercise (chest pain, breathlessness, leg fatigue).

\section{ARTERIAL BLOOD GAS MEASUREMENT}

Arterial tensions of $\mathrm{O}_{2}$ and $\mathrm{CO}_{2}$ were monitored during exercise both by direct sampling and by the transcutaneous method described below. Arterial blood was sampled from an indwelling arterial cannula sited in the radial or brachial artery of the non-dominant forearm before the test. Blood was sampled over a 30 second period with the patient at rest, half way through each level of workload, and the instant the patient stopped exercise. All

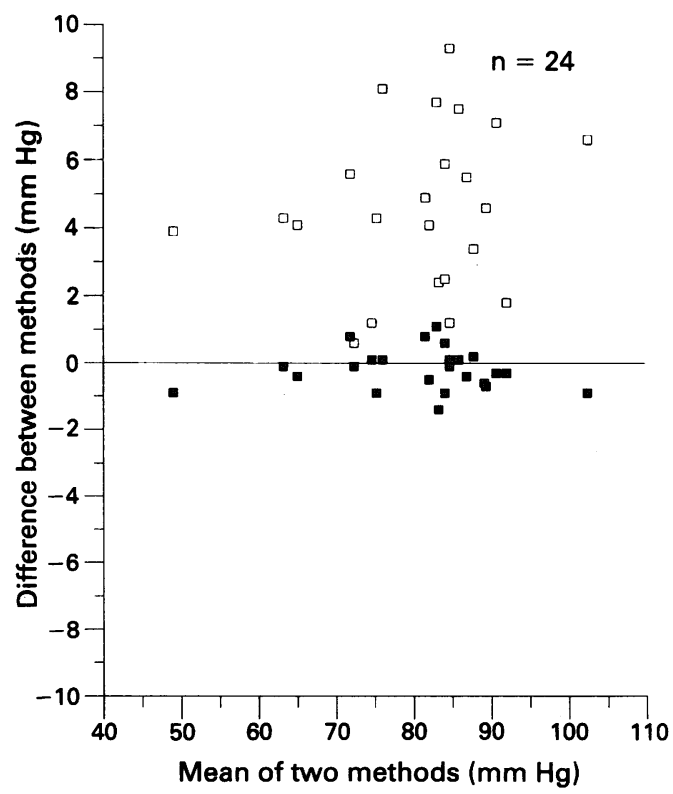

Figure 1 Scatterplot of difference between transcutaneous $\mathrm{O}_{2}$ and $\mathrm{PaO}_{2}$ (open squares) and between transcutaneous $\mathrm{CO}_{2}$ and $\mathrm{PaCO}_{2}$ (closed squares) without an in vivo calibration of transcutaneous system. Mean difference between methods: $\mathrm{O}_{2}, 0.64 \mathrm{kPa}(4.89 \mathrm{~mm} \mathrm{Hg}) ; \mathrm{CO}_{2}$, $0.02 \mathrm{kPa}(0.19 \mathrm{~mm} \mathrm{Hg})$ samples were stored in ice and analysed immediately thereafter (Corning Blood Gas Analyser 178).

\section{TRANSCUTANEOUS MEASUREMENT}

The transcutaneous $\mathrm{O}_{2}$ tensions were measured by a single $\mathrm{PO}_{2} / \mathrm{PCO}_{2}$ electrode (TINA electrode, Radiometer Ltd, Copenhagen) and its monitoring system $\left(\mathrm{T}_{\mathrm{C}} \mathrm{M} 3\right)$. Based on the manufacturer's data the typical $90 \%$ response time is 30 seconds for the $\mathrm{O}_{2}$ electrode and 60 seconds for the $\mathrm{CO}_{2}$ electrode. Accordingly the transcutaneous $\mathrm{O}_{2}$ and $\mathrm{CO}_{2}$ values noted at the end of each stage of exercise were taken to correspond to the $\mathrm{O}_{2}$ and $\mathrm{CO}_{2}$ tensions obtained by direct sampling at the mid point of each stage of exercise. All gas tensions were expressed in $\mathrm{mm} \mathrm{Hg}$ as the output of the transcutaneous system was in these units. All subjects gave informed consent and local hospital ethical committee approval was obtained to use a transcutaneous electrode heated to $45^{\circ} \mathrm{C}$ on the volar aspect of the forearm.

The arterial cannula was inserted as the first manoeuvre and thereafter the transcutaneous electrode was sited on the volar aspect of the same forearm and allowed to "settle", heating to $45^{\circ} \mathrm{C}$. When a stable reading was apparent (five minutes) the values for transcutaneous $\mathrm{O}_{2}$ and $\mathrm{CO}_{2}$ were noted and an arterial sample was drawn for comparison. The gain controls of the transcutaneous monitoring system were then adjusted so that the transcutaneous values corresponded to the directly measured arterial sample. After resting for a further two minutes the baseline transcutaneous readings were noted.

\section{DATA ANALYSIS}

The transcutaneous method of estimating $\mathrm{O}_{2}$ and $\mathrm{CO}_{2}$ tensions was compared with the direct sampling method by the procedure suggested by Bland and Altman for assessing agreement between two methods of clinical measurement. ${ }^{7}$ The mean difference between the methods for the various measurements and the limits of agreement (mean difference plus two standard deviations of the difference) were calculated.

\section{Results}

Figure 1 shows a plot of the difference between $\mathrm{O}_{2}$ and $\mathrm{CO}_{2}$ tensions for the two methods in the 24 initial readings before the in vivo calibration. There was close agreement for the arterial $\mathrm{CO}_{2}$ tension but a wider scatter for $\mathrm{O}_{2}$ with a consistent tendency for the transcutaneous method to underestimate arterial $\mathrm{O}_{2}$ tension.

A total of 140 data points were obtained from the 24 tests after in vivo calibration of the transcutaneous electrode. The range of arterial $\mathrm{PO}_{2}$ and $\mathrm{PCO}_{2}$ measured was 6.1-14.2 $\mathrm{kPa}$ and $3 \cdot 6-7 \cdot 6 \mathrm{kPa}$ respectively. Figures 2 and 3 show plots comparing the differences between transcutaneous and direct arterial blood gas estimation for $\mathrm{O}_{2}$ and $\mathrm{CO}_{2}$ respectively at each data point. The mean differ- 


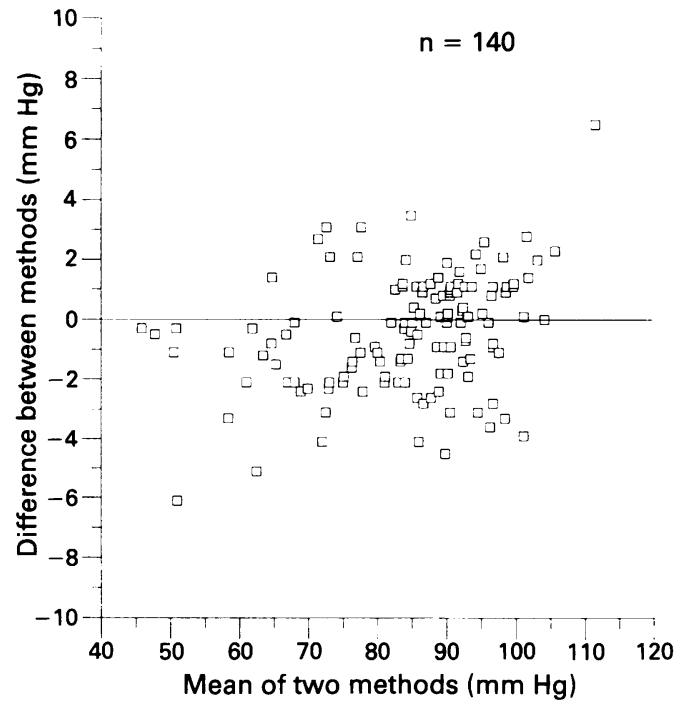

Figure 2 Scatterplot of difference between transcutaneous $\mathrm{O}_{2}$ and $\mathrm{PaO}_{2}$ with in vivo calibration of the transcutaneous system. Mean difference between methods: $0.08 \mathrm{kPa}(0.62$ $\mathrm{mm} \mathrm{Hg}$, limits of agreement 4.42 and $-3.38 \mathrm{~mm} \mathrm{Hg}$ ).

ences in the $\mathrm{O}_{2}$ and $\mathrm{CO}_{2}$ tensions measured by the two methods were $0.08 \mathrm{kPa}(0.62 \mathrm{~mm}$ $\mathrm{Hg}$, limits of agreement 4.42 and $-3.38 \mathrm{~mm}$ $\mathrm{Hg})$ and $0.02 \mathrm{kPa}(0.22 \mathrm{~mm} \mathrm{Hg}$, limits of agreement $2 \cdot 20$ and $-1.70 \mathrm{~mm} \mathrm{Hg}$ ). In all the tests changes in the transcutaneous $\mathrm{O}_{2}$ and $\mathrm{CO}_{2}$ tensions were true to the real trend of arterial $\mathrm{O}_{2}$ and $\mathrm{CO}_{2}$ tension changes as estimated by direct sampling. The data for those five patients with apparently normal resting cardiorespiratory physiology (table) were also analysed separately (fig 4) and the mean difference between methods for $\mathrm{PaO}_{2}$ was 0.05 $\mathrm{kPa}(0.34 \mathrm{~mm} \mathrm{Hg}$, limits of agreement 1.89 and $-1.2 \mathrm{~mm} \mathrm{Hg}$ ). These results compare favourably with the results over the wider range of $\mathrm{PaO}_{2}$ (fig 2) which show the applica-

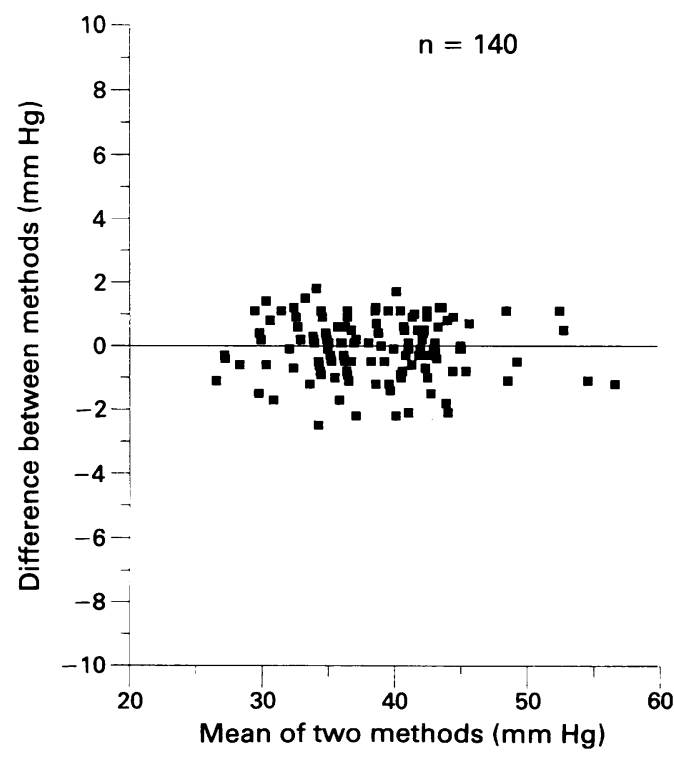

Figure 3 Scatterplot of difference between transcutaneous $\mathrm{CO}_{2}$ and $\mathrm{PaCO}_{2}$ with in vivo calibration of the transcutaneous system. Mean difference between methods: $0.02 \mathrm{kPa}(0.22 \mathrm{~mm} \mathrm{Hg}$, limits of agreement 2.20 and

$-1.70 \mathrm{~mm} \mathrm{Hg}$.

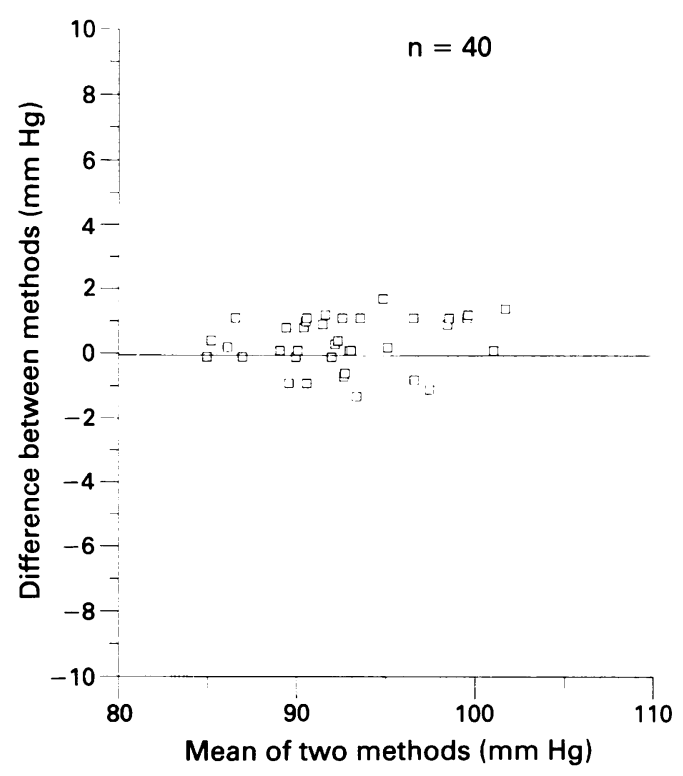

Figure 4 Scatterplot of difference between transcutaneous $\mathrm{O}_{2}$ and $\mathrm{PaO}_{2}$ in five patients with normal resting cardiorespiratory physiology. Mean difference between methods: $0.05 \mathrm{kPa}(0.34 \mathrm{~mm} \mathrm{Hg}$, limits of agreement $1 \cdot 89$ and $-1 \cdot 21 \mathrm{~mm} \mathrm{Hg}$ ).

bility of this transcutaneous system in measuring gas tensions in the normal range during exercise.

The close agreement between these two methods in following the trend of gas exchange is illustrated in fig 5 which gives the results for a patient with inappropriate hyperventilation. Figure 6 shows the data from the patient with the widest discrepancy between arterial and transcutaneous values in our

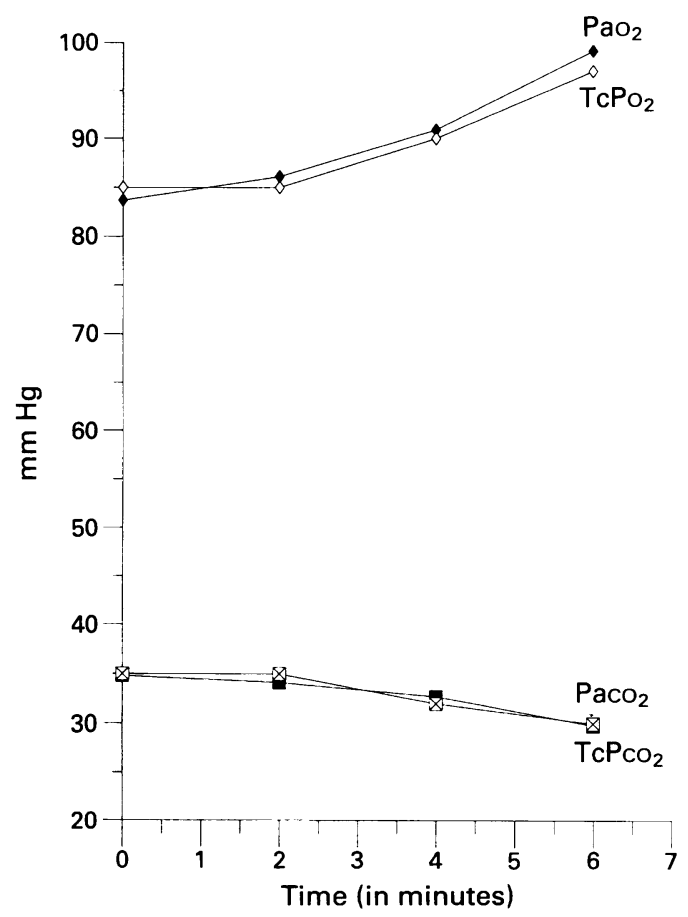

Figure 5 Blood gas changes during exercise in a 27 year old man presenting with breathlessness. Onset of symptoms at low workloads with rising $\mathrm{O}_{2}$ tensions and falling $\mathrm{CO}_{2}$ tensions suggest inappropriate hyperventilation. $\mathrm{PaO}_{2}$, $\mathrm{PaCO}_{2}$-arterial oxygen and carbon dioxide tensions; $\mathrm{TcPO}_{2}, \mathrm{TcPCO}_{2}$-transcutaneous oxygen and carbon dioxide tensions. 
Figure 6 Exercise induced changes in blood gas tensions in a 60 year old man with severe emphysema. $\mathrm{PaO}_{2}$, $\mathrm{PaCO}_{2}$-arterial oxygen and carbon dioxide tensions; $\mathrm{TcPO}_{2}, \mathrm{TcPCO}_{2}-$ transcutaneous oxygen and carbon dioxide tensions.

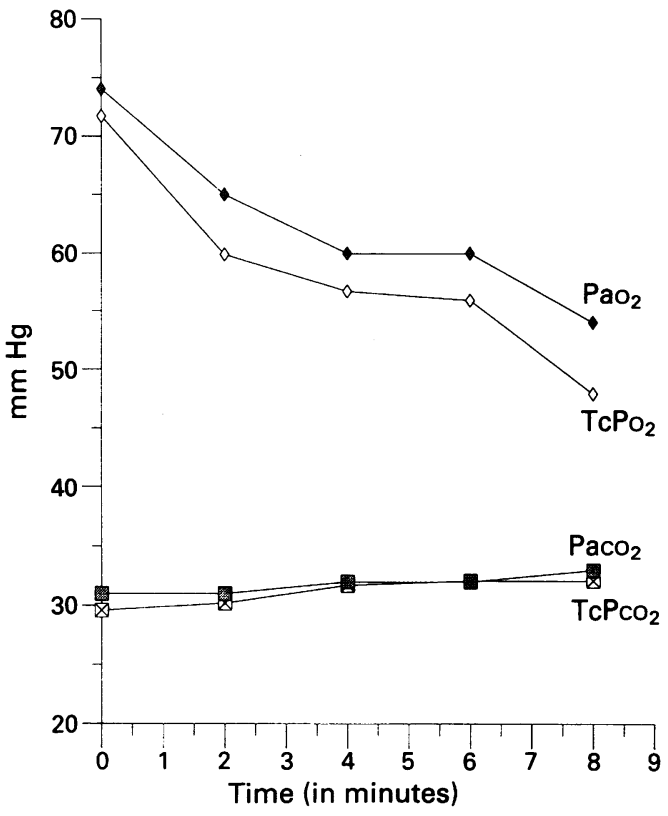

study. In this patient with emphysema the minute ventilation rapidly approached the predicted maximum and $\mathrm{PaO}_{2}$ fell sharply even at very low workloads. The trend of gas exchange as monitored from the transcutaneous system was true to the actual $\mathrm{PaO}_{2}$ values but showed a difference of $1.0 \mathrm{kPa}$ from the arterial level even though an in vivo calibration had been performed.

No test was associated with any local problem at the transcutaneous electrode site.

\section{Discussion}

The measurement of gas exchange during exercise usually involves arterial cannulation. ${ }^{8}$ Although this procedure is safe in experienced hands, it may be associated with significant complications. ${ }^{9}$ It would be advantageous, therefore, to have available a system which could monitor gas exchange in exercise without the potential morbidity associated with arterial cannulation. Our study suggests that a combined transcutaneous $\mathrm{O}_{2}$ and $\mathrm{CO}_{2}$ monitoring system could fulfil such a role.

Although transcutaneous $\mathrm{O}_{2}$ monitors have been shown to provide a reliable estimate of arterial oxygen trend during exercise, ${ }^{10}$ it has been pointed out that the slow response renders them unsuitable for use in exercise testing. It has been proposed that an acceptable $90 \%$ response time for a blood gas monitor should be $<20$ seconds if it is to be recommended for use in exercise testing. ${ }^{1}$ Transcutaneous systems, especially the $\mathrm{CO}_{2}$ electrodes, have response times of the order of 45-60 seconds and clearly do not fulfil such stringent criteria. We have adapted our exercise protocol, however, to enable the system to provide reliable information on the state of gas exchange during exercise.

Firstly, the electrode was heated to the highest recommended temperature $\left(45^{\circ} \mathrm{C}\right)$ as the higher temperature is associated with a decrease in response time. Secondly, to pre- vent abrupt and large changes in blood gas tensions a protocol of gradual workload increments was employed with a two minute exercise interval for each workload. Although some protocols employ workload increments at one minute intervals, the two minute stepup has been well tolerated in our experience across a range of cardiorespiratory problems.

The results also draw attention to the advantages of using a combined $\mathrm{O}_{2}$ and $\mathrm{CO}_{2}$ monitor. In addition to enabling the calculation of the alveolar-arterial $\mathrm{O}_{2}$ difference and dead space/tidal volume ratio which are more specific indicators of the function of the pulmonary gas exchange mechanism, measuring transcutaneous $\mathrm{CO}_{2}$ during exercise aids the detection of inappropriate hyperventilation as illustrated in fig 5 .

The data from the initial transcutaneous readings and arterial blood sample indicate the advantage of an in vivo calibration to improve the accuracy of the transcutaneous system. While the need for an arterial puncture necessarily detracts from the non-invasive nature of the technique, we would suggest that a considerable advantage over traditional cannulation is retained. Our study suggests that this system is robust and reliable for monitoring a trend in gas exchange alterations during exercise over the range from apparently "normal" persons (fig 4) to those with advanced cardiorespiratory diseases. We have not, however, undertaken studies in healthy volunteers, believing that insertion of arterial cannula might prove difficult to justify.

The transcutaneous system compares favourably with other non-invasive systems of estimating gas exchange during exercise. Arterial $\mathrm{O}_{2}$ saturation $\left(\mathrm{SaO}_{2}\right)$ by pulse oximetry has been widely used. The main limitation of the system is the shape of the oxygen dissociation curve; significant changes in arterial $\mathrm{O}_{2}$ tension can occur without major changes in $\mathrm{SaO}_{2}$ when arterial $\mathrm{O}_{2}$ is $>8 \mathrm{kPa}$. The other non-invasive technique for indicating the state of gas exchange is end tidal $\mathrm{CO}_{2}$ monitoring $\left(\mathrm{PETCO}_{2}\right)$. The $\mathrm{PETCO}_{2}$ is an approximation of $\mathrm{PaCO}_{2}$ only under circumstances of ventilation/perfusion homogeneity and uniform emptying of alveolar units. ${ }^{11}$ Neither of these conditions can be assumed in patients with cardiopulmonary disorders.

The findings of our study suggest that a combined transcutaneous $\mathrm{O}_{2}$ and $\mathrm{CO}_{2}$ electrode can be used to provide a reliable noninvasive estimate of gas exchange in exercise provided a maximal permissible temperature is selected $\left(45^{\circ} \mathrm{C}\right)$, together with gradual stepups in workload at two minute intervals. The technique circumvents the need for arterial cannulation, but is enhanced by an initial in vivo calibration. The system may be particularly valuable in following gas exchange trends in patients undergoing repeated exercise tests.

1 Clark JS, Votteri B, Ariagno RL, Cheung P, Eichhorn JH, Fallat R, et al. Non-invasive assessment of blood gases. Am Rev Respir Dis 1992;145:220-32. 
2 Payne JP, Severinghaus JW, eds. Pulse oximetry. Berlin: Spring-Verlag, 1986.

3 Severinghaus JW, Bradley AF. Electrodes for blood $\mathrm{Po}_{2}$ and $\mathrm{PCO}_{2}$ determination. $\mathcal{F}$ Appl Physiol 1958;13:515-20.

4 Yamanaka MK, Sue DY. Comparison of arterial end-tidal $\mathrm{PCO}_{2}$ difference and dead space/tidal volume ratio in respiratory failure. Chest 1987;92:832-5.

5 Beran AV, Huxtable RF, Black KS, Shigezawa GY Yeung $\mathrm{HN}$. Investigation of transcutaneous $\mathrm{O}_{2}-\mathrm{CO}_{2}$ sensors and their application on human adults and newborns. In: Huch A, Huch R, Lucey J, eds. Continuous transcutaneous blood gas monitoring. New York: Liss, 1979:421-32.

6 Mahutte CK, Michiels TM, Hassell KT, Trueblood DM. Evaluation of a single transcutaneous $\mathrm{PO}_{2}-\mathrm{PCO}_{2}$ sensor in adult patients. Crit Care Med 1984;12:1063-6.

7 Bland MJ, Altman DG. Statistical methods for assessing agreement between two methods of clinical measurement. Lancet 1986;i:306-10.

8 McKelvie RS, Jones NL. Cardiopulmonary exercise testing. Clin Chest Med 1989;10:277-91.

9 Bedford RF, Wollman H. Complications of percutaneous radial artery cannulation: an objective prospective study in man. Anesthesiology 1973;38:228-36.

10 Hughes JA, Gray BJ, Hutchison DCS. Changes in transcutaneous oxygen tension during exercise in pulmonary emphysema. Thorax 1984;39:424-31.

11 Scheid P, Piiper J. Blood/gas equilibrium of carbon dioxide in lungs: a critical review. Respir Physiol 1980;39: 1-31.

\section{Origin of the word "asthma"}

Most of our old medical words come originally from Greek since Roman medicine is essentially Greek medicine at Rome. When there is a choice we more frequently use the Greek alternative-for example hepar for liver, not the Latin jecur.

In modern medical texts the word "asthma" is rightly said to be derived from the identical Greek word, but meaning "wheezing", which I don't think it does. (Greek words here will be transliterated into approximately equivalent English letters.) Asthma is a very old word. Homer uses it twice in a famous passage. In the Iliad Book 14 Hector has come up against the greater (Telamonian) Ajax, cast his spear with no effect, and is trying to withdraw. Ajax, the giant, throws a huge boulder and strikes Hector on the chest just below the neck (sternomanubrial junction?), spinning him round like a top. Hector collapses and the narrative moves on until Book 15 where it states: "ho d" argaleoi echet' asthmati .....haim' emeon". He was "gripped by (echeto) difficult (argaleot) asthma, vomiting up (emeon) blood (haima)."

To distinguish between haematemesis and haemoptysis from the history was apparently as difficult for Homer as it can be for us now. The second passage in the same book refers to his recovery, when the "asthma kai hidros"- "asthma and sweating"-ceased.

The verb that is cognate with asthma is asthmaino which appears, for example, in Book 10. Odysseus and Diomedes are chasing the Trojan, Dolon, on foot at speed over a long distance. Diomedes throws a spear over Dolon's shoulder. It sticks in the ground in front of him and stops him in his tracks. The two pursuers come up "asthmainonte". What follows is horrid. I refuse to believe that this is the first description of exercise-induced asthma.

We must go on to Hippocrates (whoever he was-probably several people) to find asthma in one of his or their Aphorisms. The first $(1,1)$ is the one about art being long, life short, usually quoted in Latin translation and just visible in the arms of the London Royal
College of Physicians. In 3,22 he includes asthma, in the plural, in a list of diseases which occur in summer, which is interesting, but it is sandwiched between angina and ileus which spoils the impact. In the Hippocratic corpus the word is used to mean accelerated difficult breathing or shortness of breath, definitely a clinical symptom. (I am grateful to Dr Peter Jones of the Department of Classics, Newcastle, for advice on this and other points.)

We have to go a long way on to find asthmatikos, asthmatic, probably to Herodotus Medicus (1st century AD) quoted by Oribasius (4th century $A D$ ). Oribasius was physician to Julian the Apostate who tried to reintroduce to Rome the worship of the Olympian gods and sent him off to sound out the long silent Oracle at Delphi which (who?) replied, in still passable hexameters, that unfortunately the old firm was no longer in practice at the address stated.

Perhaps it would be better to go backwards and see if we can find the ur-word from which asthma derives. I would like it to be ao-"blow"-for which one could make a case. It is composed of alpha and omega, the beginning and the end, and would briefly symbolise the supreme importance of our specialty of thoracic medicine, a badly needed gesture. I think I shall have to settle for awo, however, where " $w$ " is the Greek digamma, a letter which disappeared from the alphabet about the time Homer's text was being written down, equivalent to Latin " $v$ " and pronounced as English "w". Better perhaps is awemi, also "blow". From that comes eventually the Latin ventus and our English "wind". You may feel that the linguistic connection between "asthma" and "wind" is not immediately apparent, but there it is.

In short, asthma did not originally mean "wheeze" but rather "noisy breathing", "making a blowing noise", "panting", or even "groaning".

KB SAUNDERS 